\title{
Relationship between environmental exposure to cadmium and bone metabolism in a non-polluted area of Japan
}

\author{
Mitsuru Osada • Takashi Izuno • Minatsu Kobayashi • \\ Minoru Sugita
}

Received: 24 October 2010/Accepted: 16 December 2010/Published online: 21 January 2011

(C) The Japanese Society for Hygiene 2011

\begin{abstract}
Objectives The purpose of this study was to investigate the effects of environmental low-grade cadmium exposure on bone in the population of a non-polluted area. We investigated the relationship between environmental cadmium exposure (via rice intake) and bone metabolism in middle-aged and elderly women living in a non-polluted area in Japan.

Methods Four hundred and twenty-nine women over the age of 39 years (54.6 \pm 9.1 years; arithmetic mean \pm SD) participated in this study in 2003. We investigated blood and urine, and rice intake, and performed ultrasonic bone evaluation, and obtained individual information about the subjects' health. Multiple regression analysis was performed in the statistical analysis.

Results The arithmetic mean of cadmium content in rice was $70.8 \pm 44.7 \mu \mathrm{g} / \mathrm{kg}$ (AM $\pm \mathrm{SD})$. The geometric mean of daily cadmium intake ( $\mathrm{Cd}$ intake) from rice calculated based on food consumption data was $9.12 \mu \mathrm{g} /$ day (GSD 2.33). The geometric means of serum and urine cadmium concentrations were $1.57 \mu \mathrm{g} / \mathrm{l}$ (GSD 2.11) and $1.93 \mu \mathrm{g} / \mathrm{g}$ creatinine (cr.) (GSD 2.05), respectively. Multiple
\end{abstract}

M. Osada $(\bowtie) \cdot$ M. Sugita

Department of Environmental and Occupational Health,

Toho University School of Medicine,

5-21-16 Omori-nishi, Ota-ku, Tokyo 143-8540, Japan

e-mail: osadajuu@d5.dion.ne.jp

T. Izuno

Bureau of Social Welfare and Public Health,

Tokyo Metropolitan Government, Tokyo, Japan

M. Kobayashi

Laboratory of Public Health Nutrition,

Department of Food Science, Faculty of Home Economics,

Otsuma Women's University, Tokyo, Japan regression analysis showed positive correlations between (1) urinary free deoxypyridinoline (FDPD-U) and $\mathrm{Cd}$ intake $(p<0.05)$, (2) urinary cross-linked N-telopeptides of type I collagen (NTx-U) and Cd intake $(p<0.05)$, and (3) FDPD-U or NTx-U and cadmium concentration in urine $(p<0.01)$. No significant correlation between the parameters of ultrasonic bone evaluation and cadmium associated biomarkers was observed.

Conclusions The results of the present study suggest the possibility of bone metabolic disorder induced by environmental low-grade cadmium exposure. With respect to osteoporosis, a long-term follow-up survey is required to assess the tolerable intake of cadmium in environmental exposure.

Keywords Environmental exposure to cadmium . Cadmium intake from rice - Ultrasonic bone evaluation . Non-polluted area $\cdot$ Bone metabolism

\section{Introduction}

Cadmium is a toxic metal which adversely affects human health. Several studies have investigated the adverse health effects of cadmium via environmental exposure in nonpolluted areas, while numerous studies have reported occupational cadmium exposure and environmental exposure in polluted areas including the Jinzu River basin in Japan, where the infamous itai-itai ("ouch-ouch") disease had been prevalent [1]. The Food and Agriculture Organization of the United Nations (FAO) and Joint Expert Committee of Food Additives and Contaminants (JECFA) of the World Health Organization (WHO) proposed a provisional tolerable weekly intake (PTWI) of $7 \mu \mathrm{g} / \mathrm{kg}$ body weight/week of cadmium in 1993 [2]. After various 
investigations at subsequent meetings, the committee established a provisional tolerable monthly intake (PTMI) of $25 \mu \mathrm{g} / \mathrm{kg}$ body weight/month at the 73rd meeting of the JECFA in 2010 [3]. This risk assessment was estimated based on data from occupationally exposed workers. There is some controversy over whether the present PTWI of $7 \mu \mathrm{g} / \mathrm{kg}$ body weight/week is applicable to populations exposed to low-grade environmental cadmium via food, beverages, air, dust, smoking, etc. For non-smokers, the main source, almost $99 \%$ or more, of cadmium exposure in Japan is the diet [4]. In the case of Japanese who eat large amounts of rice, it is assumed that approximately $40 \%$ of the cadmium exposure from food is ingested via rice [5]. To assess the environmental low-grade cadmium body burden in Japan, it is worth investigating the cadmiuminduced effect via rice. Cadmium content in polished rice shows geographical differences in non-polluted areas. International surveys have revealed that polished rice harvested in Japan retained high concentrations of cadmium, especially in the Hokuriku region, compared with other countries in Asia and Europe, even though cadmium content in Japanese rice has been reduced in recent years mainly by field reclamation of agricultural land $[5,6]$.

The biological half-time of cadmium taken into the body is relatively long, ranging from several years to tens of years [7]. Past studies have noted that intraorganic accumulation of cadmium shows maximum values in the fifth decade of life [7-9]. Most of the patients suffering from itai-itai disease were middle-aged and elderly women. Iron deficiency, which is prevalent in women, creates a significant risk for cadmium exposure [10-13]. It was considered reasonable to investigate the data of middle-aged and elderly women because the toxic effect of cadmium in each of the organs was remarkable in female subjects in their fifties.

We investigated the relationship between osteoporosis and environmental low-grade exposure to cadmium in middle-aged and elderly women living in a non-polluted area of the Hokuriku region, on the west coast of the Sea of Japan, where cadmium intake via rice has been reported to be relatively high [14].

\section{Subjects, materials, and methods}

From April to December 2003, middle-aged and elderly women who had annual general health checkups conducted by Joetsu City and adjacent cities, towns, or villages under the Health and Medical Service Act for the Aged, or at their workplace in the Joetsu region under the Industrial Safety and Health Act for workers were selected. They were all over the age of 39 years. Four hundred and twenty-nine of 521 subjects who had annual general health checkups agreed to participate in this study. This investigation was

performed at the cities, towns, villages, and workplaces where cooperation was obtained. No soil pollution by cadmium has ever been reported in this area. The proportion of participants in this study to the whole subject cohort was $2.5 \%$ in those who should have the annual general health checkups under the Health and Medical Service Act for the Aged in Joetsu city and adjacent cities, towns, or villages, and $32.2 \%$ those who should have the annual general health checkups under the Industrial Safety and Health Act.

Two types of self-administered questionnaires, and pedometers, were distributed to the participants in advance of the health checkups. They responded to the questionnaires and recorded the number of steps walked daily before measurements of height and weight were taken. It takes about $40 \mathrm{~min}$ to complete the questionnaires. One of the questionnaires asked about the general health condition of participants, with items such as birth date, lifestyle, history of place of residence (village/town/city), and present medical history. The other questionnaire, on diet history, has been described as well-validated [15-19] (Table 1). We used this questionnaire to determine the average amount of rice intake in the months prior to the investigation. At the time of the health checkups, we collected the questionnaires and samples of rice which the participants usually ate and brought from home. Three hundred and thirty-seven homegrown rice samples and 92 commercially available rice samples were collected. We measured the participants' height and weight, and collected blood and urine samples from them. Quantitative ultrasound (QUS) bone measurements were also performed at this time.

It is difficult to evaluate the adverse effects of cadmium among smokers because smokers are exposed to various kinds of chemicals including cadmium in tobacco smoke. Therefore, 29 smokers in the homegrown rice group and

Table 1 An outline of questions in the questionnaire

\begin{tabular}{l} 
Age at the investigation \\
Age of menarche \\
Menstrual cycle \\
Delivery \\
Lactation \\
Anamnesis \\
Place of residence (village/ \\
town/city) \\
Occupation \\
Muscular labor \\
Habit of exercise \\
Smoking \\
Origin of rice \\
Habit of food intake \\
Diet \\
Intake of well water \\
Amount of rice intake \\
\hline
\end{tabular}


five smokers in the commercially available rice group were excluded from this analysis. Six subjects who had histories of chronic renal diseases were also excluded. Subjects whose current history included anemia (15 females) and diabetes mellitus ( 7 females who had not been diagnosed with diabetic nephropathy) were included in order to analyze the health effects of cadmium exposure among these groups. We investigated the data of 389 subjects and collected 302 homegrown rice samples and 87 commercially available rice samples. None of the 389 subjects had ever been exposed to cadmium occupationally. No subject had a history of residence in a reported cadmium polluted area [20].The average [arithmetic mean \pm arithmetic standard deviation $(\mathrm{AM} \pm \mathrm{SD})]$ age was $54.6 \pm 9.1$ years (minimum age 39 years and maximum 77).

Bone measurements by QUS were performed at the right calcaneus in each subject, using an ultrasound bone evaluation device (AOS-100: ALOKA, Tokyo, Japan). Three QUS parameters were measured: (1) speed of sound (SOS; $\mathrm{m} / \mathrm{s}$ ), which reflects the bone density of the calcaneus, (2) the transmission index (TI; $\mu \mathrm{s})$, which reflects cancellous bone volume, and (3) the osteo sono-assessment index $\left(\mathrm{OSI} ; \mathrm{m}^{2} / \mathrm{s}\right)$, which reflects bone elasticity [21-23]. The OSI value was calculated by the following equation: (TI) $\times(\mathrm{SOS})^{2}$, where SOS is ultrasound velocity when ultrasound is transmitted through the calcaneus and TI is the full width at half maximum of the first ultrasonic wave detected through the calcaneus. Bone measurement by QUS was applied to the clinical diagnosis of osteoporosis in the early 1990s in Japan. Ultrasonic evaluation has several advantages over bone mass measurement techniques. Measurement of ultrasonic evaluation requires no radiation, and the equipment is more portable and less costly than bone densitometry equipment such as that required for dual-energy X-ray absorptiometry (DXA) and quantitative computed tomography [24]. It takes only about 5-8 $\mathrm{min}$, to measure bone properties using ultrasonic evaluation [21]. Some studies have reported that this technique was useful for assessment of the risk of osteoporotic fracture in epidemiologic investigations [24, 25]. However, bone measurements by QUS are influenced by the temperature of the atmosphere and the subject's skin, dirt on the skin of the subject's heel, the location of the subject's heel on the equipment, and the volume of subcutaneous fat tissue [26]. The measurement of DXA is the standard method for evaluating individual bone mineral density of the lumbar spine. We used QUS to evaluate bone mass properties in this study for the reasons described above, especially since individual examination time is limited in the annual general health checkups.

The number of steps walked by the subjects was measured with a pedometer (HJ-005: OMRON HEALTHCARE, Tokyo, Japan) for three consecutive days. The mean number of steps walked by each subject per day was calculated to evaluate the correlation between steps walked and other parameters.

The questionnaires and samples were checked twice by nurses and nutritionists. A portion, $2 \mathrm{~g}$ (fresh weight), of raw rice was wet-ashed by heating in the presence of mineral acids, as described previously [27] until a clear residue (approx. $0.3 \mathrm{ml}$ ) was obtained. The residue was then diluted to a volume of $10 \mathrm{ml}$ by the addition of deionized water, and the diluted wet ash was subjected to analysis for cadmium by inductively coupled plasma mass spectrometry (ICP-MS). The ICP-MS apparatus (connected to an autosampler) was a product of Seiko Instruments (Tokyo, Japan). Isotopes were selected for cadmium determination, and indium (In) and thallium (Tl) were used as the internal standards in the preparation of calibration curves. The recovery was approximately $95 \%$ for cadmium, and the accuracy, when examined with bovine liver, typical diet, and rice flour as reference materials, was $96-118 \%$ (104\% average). The detection limit was $0.1 \mathrm{ng} / \mathrm{g}$ (when a signal/noise ratio of 2 was taken), which was considered sufficient. In practice, the autosampler could accommodate 50 samples in a series. The determination of cadmium in one series (including the input of operation conditions to the system) took $2.5-3 \mathrm{~h}$, making it possible to measure 100-150 samples per day.

Peripheral blood samples, with one drop of $7.5 \%$ nitric acid added to stabilize the cadmium content, were centrifuged. Then the serum samples were stored at $-80^{\circ} \mathrm{C}$ until analysis. Urine samples, with one drop of $0.75 \%$ nitric acid added to stabilize the cadmium content, were stored at $-80^{\circ} \mathrm{C}$ until analysis. The cadmium concentrations were measured by flameless atomic absorption spectrometry, using the Z-8100 (Hitachi, Hitachi City, Ibaraki, Japan) apparatus. Cadmium measurements were checked using the cadmium standard (Kanto Chemical, Tokyo, Japan). All items in contact with the samples, including plastic bottles, tubes, and syringes, had no detectable cadmium contamination.

$\beta_{2}$-Microglobulin in urine ( $\beta_{2}$-MG-U) and $N$-acetyl- $\beta$-Dglucosaminidase in urine (NAG-U) were measured as indicators of renal dysfunction. Blood and urine samples were obtained in the morning from 9:00 a.m. to noon. Second morning urine samples were collected at the health checkup location. After collection of the urine sample, the $\mathrm{pH}$ was checked by a $\mathrm{pH}$ indicator method (Eiken Chemical, Nogi Town, Tochigi, Japan) and kept neutral (pH 4-8) without any regulation process, then preserved at $-80^{\circ} \mathrm{C}$ until analysis. The concentrations of $\beta_{2}-\mathrm{MG}-\mathrm{U}$ were measured by a latex agglutination method (Eiken Chemical). The concentration of NAG-U was measured by a rate method (Shionogi, Settsu City, Osaka, Japan). Creatinine in urine was measured by an enzyme method (Kanto Chemical). Free deoxypyridinoline in urine (FDPD-U) and 
cross-linked N-telopeptides of type I collagen in urine (NTx-U) were measured by enzyme immunoassay. Serum bone-specific alkaline phosphatase (BAP-S) was measured by polyacrylamide gel electrophoresis.

Stock solutions for certified references (1000 ppm) and mineral acids of trace element analysis grade were purchased from Wako Pure Chemicals (Osaka, Japan). Standard reference materials of bovine liver (NBS 1577b), and rice flour (NBS 1588) were obtained from the National Institute of Standards and Technology (Gaithersburg, MD, USA) and that of rice flour (NIES 10a, 10b, and 10c) was obtained from the National Institute for Environmental Sciences (Tsukuba City, Ibaraki, Japan). Deionized water was prepared by filtration of city water through a Millipore-O system (Millipore, Molsheim, France).

We calculated total dietary cadmium intake from rice by multiplying the consumption amount and cadmium concentration in rice (Cd-R), then we calculated the total daily cadmium intake from food based on the average Japanese cadmium intake levels cited in the total diet study conducted by the National Institute of Health Science in 2002 [28]. This calculation is based on the following equations.

[Total dietary cadmium intake from rice per day]

$=[$ Consumption amount of rice per day $] \times[\mathrm{Cd}-\mathrm{R}]$,

[Total daily cadmium intake from food]

$=$ [Total dietary cadmium intake from rice per day]

$\times$ [Average Japanese total cadmium intake from food per day in 2002]

$\div$ [Average Japanese cadmium intake from rice per day in 2002]

According to this survey, the average Japanese total cadmium intake from food in 2002 was $26.0 \mu \mathrm{g} / \mathrm{day}$, and from rice it was $10.8 \mu \mathrm{g} / \mathrm{day}$, so we applied $41.5 \%$ as the proportion of total dietary cadmium intake from rice per day to total daily cadmium intake from food. Then we calculated the weekly cadmium intake per body weight from the total daily cadmium intake to compare the calculated amount with the present PTWI level [2].

Concentrations are expressed on a fresh weight basis. A preliminary analysis of the distribution of the concentrations showed that arithmetic standard deviations (ASD) were often greater than one-third of the corresponding means [arithmetic mean (AM)], as observed previously [6, 29]. Thus, a natural logarithmic distribution was considered $[6,29,30]$ so that geometric means (GMs) and standard deviations (GSDs) were taken as representative parameters of distribution. In calculating the GM and GSD, the value below the detection limit was assumed to be half the detection limit. Further, multiple regression models were used to analyze the relationship between the indicator of cadmium burden and renal function or bone metabolism, adjusting the effect of age with SAS statistical analysis software version 8.2 (SAS Institute, Cary, NC, USA).

\section{Ethical considerations}

All participants in this study were informed about the content and objectives of this study and gave their informed consent to participate. Local ethics committees of Toho University School of Medicine gave permission to perform this study (Admission number: 14-046).

\section{Results}

The mean $(\mathrm{AM} \pm \mathrm{SD}$ ) $\mathrm{Cd}-\mathrm{R}$ was $70.8 \pm 44.7 \mu \mathrm{g} / \mathrm{kg}$ (minimum $0.2 \mu \mathrm{g} / \mathrm{kg}$, maximum $256.4 \mu \mathrm{g} / \mathrm{kg}$ ). The mean cadmium intake $(\mathrm{Cd}$ intake) from rice $(\mathrm{AM} \pm \mathrm{SD})$ was $1.61 \pm 1.17 \mu \mathrm{g} / \mathrm{kg}$ body weight/week (minimum $0.006 \mu \mathrm{g} /$ $\mathrm{kg}$ weight/week, maximum $7.761 \mu \mathrm{g} / \mathrm{kg}$ body weight/week). The mean daily Cd intake from rice (GM) was $9.12 \mu \mathrm{g} /$ day (GSD 2.33; minimum $0.04 \mu \mathrm{g} /$ day, maximum $51.27 \mu \mathrm{g} /$ day). The mean serum cadmium concentration (Cd-B: GM) was $1.57 \mu \mathrm{g} / \mathrm{l}$ (GSD 2.11; minimum $0.50 \mu \mathrm{g} / \mathrm{l}$, maximum $10.00 \mu \mathrm{g} / \mathrm{l})$. The mean cadmium concentration in urine (Cd-U: GM) was $1.93 \mu \mathrm{g} / \mathrm{g}$ creatinine (cr.) (GSD 2.05; minimum $0.29 \mu \mathrm{g} / \mathrm{g}$ cr., maximum $11.83 \mu \mathrm{g} / \mathrm{g}$ cr.) (Table 2).

In the first evaluation, we assessed partial correlation coefficients between parameters. As age had a statistically significant relation to all parameters but number of steps walked, we investigated relationships between parameters adjusting for age. Table 3 shows the age-adjusted correlation coefficients between parameters. We mainly investigated the relationships between cadmium-associated biomarkers and bone metabolic markers, as well as ultrasonic bone evaluation parameters, because previous studies reported that bone absorption was accelerated by cadmium intake. The other parameters will be investigated in a further study [31-42]. Correlation between two substances in urine was calculated from the original measured values, adjusted by age and logarithmic transformed creatinine, while correlations between substances in urine and other parameters were calculated from values in urine corrected by urinary creatinine adjusted by age [43]. As shown in Table $3, \log \mathrm{Cd}-\mathrm{U}$ was positively associated with $\log \mathrm{Cd}$ intake and $\log \mathrm{Cd}-\mathrm{B}$, with correlation coefficients of 0.134 0.384 , respectively. In regard to skeletal biomarkers, log FDPD-U was positively associated with $\log \mathrm{Cd}$ intake and $\log \mathrm{Cd}-\mathrm{U}$, with correlation coefficients of 0.106 and 0.152 , respectively, and $\log \mathrm{NTx}-\mathrm{U}$ showed the same trend as $\log$ FDPD-U, with correlation coefficients of 0.125 and 0.163 , respectively, while OSI was not associated with $\log \mathrm{Cd}-\mathrm{U}$, $\log \mathrm{Cd}-\mathrm{B}$, or $\log \mathrm{Cd}$ intake. 
Table 2 Characteristics of participants $(N=389)$

\begin{tabular}{|c|c|c|c|c|}
\hline & Mean & SD & Minimum & $\overline{\text { Maximum }}$ \\
\hline Age (years) & $54.6(\mathrm{AM})$ & 9.1 & 39 & 77 \\
\hline Height $(\mathrm{cm})$ & $153.4(\mathrm{AM})$ & 6.3 & 124.0 & 168.0 \\
\hline Weight $(\mathrm{kg})$ & $53.2(\mathrm{AM})$ & 7.3 & 34.0 & 80.8 \\
\hline Body mass index (BMI) & $22.6(\mathrm{AM})$ & 2.8 & 17.0 & 35.0 \\
\hline $\mathrm{Cd}-\mathrm{B}(\mu \mathrm{g} / \mathrm{l})$ & $1.57(\mathrm{GM})$ & 2.11 & 0.50 & 10.00 \\
\hline Cd-U ( $\mu \mathrm{g} / \mathrm{g}$ cr.) & $1.93(\mathrm{GM})$ & 2.05 & 0.29 & 11.83 \\
\hline $\mathrm{Cd}$ intake from rice $(\mu \mathrm{g} /$ day $)$ & $9.12(\mathrm{GM})$ & 2.33 & 0.04 & 51.27 \\
\hline $\mathrm{Cd}-\mathrm{R}(\mu \mathrm{g} / \mathrm{kg})$ & $70.83(\mathrm{AM})$ & 44.68 & 0.21 & 256.39 \\
\hline$\beta_{2}-\mathrm{MG}-\mathrm{U}(\mu \mathrm{g} / \mathrm{g}$ cr. $)$ & $105.37(\mathrm{GM})$ & 2.10 & 3.90 & 1096.00 \\
\hline NAG-U (U/g cr.) & $4.68(\mathrm{GM})$ & 1.58 & 1.43 & 23.18 \\
\hline NTx-U (nmol BCE/mmol cr.) & $37.55(\mathrm{GM})$ & 1.55 & 11.25 & 155.19 \\
\hline FDPD-U (nmol/mmol cr.) & $5.61(\mathrm{GM})$ & 1.45 & 0.11 & 21.90 \\
\hline BAP-S (U/l) & $22.81(\mathrm{GM})$ & 1.47 & 8.60 & 62.99 \\
\hline OSI $\left(\mathrm{m}^{2} / \mathrm{s}\right)$ & 2.57 (AM) & 0.32 & 1.92 & 3.67 \\
\hline TI $(\mu \mathrm{s})$ & 1.07 (AM) & 0.10 & 0.84 & 1.38 \\
\hline $\operatorname{SOS}(\mathrm{m} / \mathrm{s})$ & $1549.60(\mathrm{AM})$ & 25.40 & 1477.00 & 1634.00 \\
\hline
\end{tabular}

$A M$ arithmetic mean with arithmetic standard deviation, $G M$ geometric mean with geometric standard deviation, $S D$ standard deviation, $O S I$ osteo sono-assessment index $\left(\mathrm{m}^{2} / \mathrm{s}\right), C d-B$ Cd concentration in blood $(\mu \mathrm{g} / \mathrm{l}), C d-U \mathrm{Cd}$ concentration in urine $(\mu \mathrm{g} / \mathrm{g}$ creatinine [cr.]), $C d-R$ cadmium concentration in rice, $\beta_{2}-M G-U \beta_{2}$-microglobulin in urine ( $\mu \mathrm{g} / \mathrm{g}$ cr.), $N A G-U N$-acetyl- $\beta$-D-glucosaminidase in urine (U/g cr.), $F D P D-U$ free deoxypyridinoline in urine (nmol/mmol cr.), BAP-S bone-alkaline phosphatase in serum (U/l), $N T x$ - $U$ cross-linked N-telopeptides of type I collagen in urine (nmol BCE/mmol cr.), BCE Bone Collagen Equivalents, TI transmission index (the full width at half maximum of the first ultrasonic wave detected through the calcaneus), SOS speed of sound

Table 3 Age-adjusted correlation coefficients

\begin{tabular}{|c|c|c|c|c|c|c|c|c|c|c|c|}
\hline & OSI & BMI & $\begin{array}{l}\text { Steps } \\
\text { walked }\end{array}$ & $\begin{array}{l}\log C d \\
\text { intake }\end{array}$ & $\begin{array}{l}\log \\
\text { Cd-B }\end{array}$ & $\begin{array}{l}\log \\
\text { Cd-U }\end{array}$ & $\begin{array}{l}\log \\
\beta_{2}-\mathrm{MG}-\mathrm{U}\end{array}$ & $\begin{array}{l}\log \\
\text { NAG-U }\end{array}$ & $\begin{array}{l}\log \\
\text { FDPD-U }\end{array}$ & $\begin{array}{l}\log \\
\text { BAP-S }\end{array}$ & $\begin{array}{l}\log \\
\text { NTX-U }\end{array}$ \\
\hline \multicolumn{12}{|l|}{ OSI } \\
\hline BMI & $0.273 * *$ & & & & & & & & & & \\
\hline Steps walked & 0.035 & -0.064 & & & & & & & & & \\
\hline $\log \mathrm{Cd}$ intake & -0.030 & -0.056 & 0.030 & & & & & & & & \\
\hline $\log \mathrm{Cd}-\mathrm{B}$ & 0.003 & $0.118^{*}$ & 0.020 & 0.058 & & & & & & & \\
\hline $\log \mathrm{Cd}-\mathrm{U}$ & 0.009 & 0.017 & 0.021 & $0.134 * *$ & $0.384 * *$ & & & & & & \\
\hline $\log \beta_{2}-\mathrm{MG}-\mathrm{U}$ & -0.022 & -0.072 & -0.014 & -0.036 & 0.011 & -0.089 & & & & & \\
\hline $\log \mathrm{NAG}-\mathrm{U}$ & -0.087 & 0.052 & -0.058 & 0.096 & 0.086 & $0.299 * *$ & $0.169 * *$ & & & & \\
\hline $\log$ FDPD-U & -0.028 & 0.059 & -0.045 & $0.106^{*}$ & 0.090 & $0.152 * *$ & 0.030 & $0.290 * *$ & & & \\
\hline $\log$ BAP-S & $-0.128^{*}$ & $0.157 * *$ & 0.018 & 0.030 & 0.085 & 0.057 & $0.115^{*}$ & 0.047 & $0.296 * *$ & & \\
\hline $\log$ NTx-U & $-0.162 * *$ & -0.008 & 0.007 & $0.125^{*}$ & 0.038 & $0.163 * *$ & $0.162 * *$ & $0.152 * *$ & $0.390 * *$ & $0.519 * *$ & \\
\hline
\end{tabular}

OSI osteo sono-assessment index $\left(\mathrm{m}^{2} / \mathrm{s}\right), C d$ intake $\mathrm{Cd}$ intake from rice/day $(\mu \mathrm{g} / \mathrm{day}), C d-B \mathrm{Cd}$ concentration in blood $(\mu \mathrm{g} / \mathrm{l}), C d-U \mathrm{Cd}$ concentration in urine ( $\mu \mathrm{g} / \mathrm{g} \mathrm{cr}$.), $\beta_{2}-M G-U \beta_{2}$-microglobulin in urine $(\mu \mathrm{g} / \mathrm{g} \mathrm{cr}$.), $N A G$ - $U N$-acetyl- $\beta$-D-glucosaminidase in urine (U/g cr.), $F D P D$ $U$ free deoxypyridinoline in urine (nmol/mmol cr.), $B A P-S$ bone-alkaline phosphatase in serum (U/l), $N T x$ - $U$ cross-linked N-telopeptides of type I collagen in urine (nmol BCE/mmol cr.), BCE Bone Collagen Equivalents

$* p<0.05 ; * * p<0.01$

We assessed the relationship between bone metabolic indices and cadmium-associated parameters using multiple regression analysis (Table 4). Partial regression coefficients between log FDPD-U and cadmium-associated parameters were all lower than 0.25. Partial regression coefficients between log NTx-U and cadmium-associated parameters were also lower than 0.25 [43]. These results suggest that environmental cadmium exposure does not strongly influence bone metabolism.

Although we investigated the subjects' history of osteoporotic fracture by questionnaire, we could not discriminate individual fractures from non-osteoporotic fractures. 
Table 4 Partial regression coefficients of multiple regression analysis

\begin{tabular}{|c|c|c|c|c|c|c|c|c|c|}
\hline \multirow[t]{2}{*}{ Dependent variable } & \multicolumn{9}{|c|}{ Independent variables } \\
\hline & Age & BMI & Steps walked & $\log \mathrm{Cd}$-intake & $\log \mathrm{Cd}-\mathrm{U}$ & $\log \beta_{2}-\mathrm{MG}-\mathrm{U}$ & $\log$ NAG-U & $\log$ Crea-U & $R^{2}$ \\
\hline $\log$ FDPD-U & $0.115 * *$ & 0.031 & -0.021 & $0.052 *$ & - & 0.019 & - & $0.887 * *$ & 0.790 \\
\hline $\log$ FDPD-U & $0.094 * *$ & 0.027 & -0.020 & - & $0.100 * *$ & 0.025 & - & $0.814 * *$ & 0.792 \\
\hline $\log$ FDPD-U & $0.077 * *$ & 0.020 & -0.011 & 0.037 & - & - & $0.223 * *$ & $0.713 * *$ & 0.806 \\
\hline $\log$ FDPD-U & $0.068 * *$ & 0.017 & -0.011 & - & 0.047 & - & $0.212 * *$ & $0.690 * *$ & 0.805 \\
\hline $\log$ NTx-U & $0.221 * *$ & -0.002 & 0.008 & $0.060 *$ & - & $0.096 * *$ & - & $0.841 * *$ & 0.780 \\
\hline $\log$ NTx-U & $0.196 * *$ & -0.007 & 0.009 & - & $0.119 * *$ & $0.103 * *$ & - & $0.755^{* *}$ & 0.784 \\
\hline $\log$ NTx-U & $0.213 * *$ & -0.011 & 0.010 & $0.050 *$ & - & - & $0.121 * *$ & $0.798 * *$ & 0.778 \\
\hline $\log$ NTx-U & $0.199 * *$ & -0.015 & 0.009 & - & $0.085^{*}$ & - & $0.099 *$ & $0.758 * *$ & 0.779 \\
\hline
\end{tabular}

$F D P D-U$ free deoxypyridinoline concentration in urine (nmol/l), $N T x-U$ cross-linked N-telopeptide of type I collagen concentration in urine (nmol BCE/l), BMI body mass index, Steps walked steps/day, $C d$-intake $\mathrm{Cd}$ intake from rice/day ( $\mu \mathrm{g} / \mathrm{day}), C d-U \mathrm{Cd}$ concentration in urine ( $\mu \mathrm{g} / \mathrm{l})$, $\beta_{2}-M G-U \beta_{2}$-microglobulin concentration in urine $(\mu \mathrm{g} / \mathrm{l}), N A G-U N$-acetyl- $\beta$-D-glucosaminidase concentration in urine (U/l), Crea- $U$ creatinine concentration in urine $(\mathrm{g} / \mathrm{l}), R^{2}$ coefficient of determination

$* p<0.05 ; * * p<0.01$

Neither the exact location of a fracture nor a detailed description of the mechanism of the forces producing the fracture was given in most of these questionnaires, and a detailed follow-up survey for all participants who had histories of fractures was impossible. Therefore, we did not assess the relationship between cadmium exposure and bone metabolic biomarkers from the viewpoint of each participant's history of osteoporotic fractures.

The influence of menopause on environmental cadmium burden on the human body was assessed. The NTx-U value was positively associated with $\beta_{2}$-MG-U $(p<0.01)$ and BAP-S was positively associated with NAG-U $(p<0.01)$ in premenopausal women, while there was no significant correlation between NTx-U and $\beta_{2}$-MG-U or between BAP-S and NAG-U in postmenopausal women. In evaluating correlation coefficients in premenopausal and postmenopausal women, the correlation coefficient between NTx-U and $\beta_{2}-\mathrm{MG}-\mathrm{U}$ was significantly greater among premenopausal women than postmenopausal women $(p<0.05)$. The correlation coefficient between BAP-S and NAG-U was significantly greater among premenopausal women than postmenopausal women $(p<0.01)$.

Frequency of pregnancy and breast-feeding did not significantly influence the correlation between bone metabolic biomarkers and cadmium-associated indices.

\section{Discussion}

With regard to the effects of environmental low-grade cadmium exposure on human health, the FAO and JECFA of WHO proposed a PTWI of $7 \mu \mathrm{g} / \mathrm{kg}$ body weight/week of cadmium based on the data of an occupationally exposed group in 1993 [2]. However, Hayashi noted that the report overestimated the influence of cadmium in environmental low-grade cadmium exposure [44]. Renal dysfunction is a well-known adverse effect of cadmium on human health. Disorders of bone metabolism such as that found in itai-itai disease are also considerable adverse effects of cadmium. Based on an investigation of patients suffering from itai-itai disease, cadmium-associated osteoporosis has been considered to be induced by the following mechanism [31, 32]: impaired activation of vitamin D via proximal renal tubular dysfunction induced by cadmium results in decreased calcium absorption through the intestine, and decreased renal tubular reabsorption of calcium and phosphate, followed by increased calcium and phosphate excretion in urine. This is the same mechanism as that found in acquired Fanconi syndrome. Studies of experimental animals and cultured tissue have demonstrated the stimulation of osteoclast-like cell formation and the activation of osteoclast-like cells resulting in the acceleration of bone resorption [33], decrease in the compression strength of bone [34], and the stimulation of calcium release from bone and the inhibition of mineralization and collagen synthesis [35] due to a cadmium burden. A decrease in bone mineral density and inhibition of bone formation before the manifestation of renal dysfunction was reported in experimental animals [36]. Furthermore, Coonse and colleagues [37] reported that cadmium induced apoptosis in the cultured osteoblast-like cell line Saos-2. Thus, the possibility of a direct effect of cadmium on bone has been suggested [38].

However, the physiological response to cadmium varies greatly among animal species. The results obtained from experimental animals or cultured tissue cannot always be extrapolated to the human body. Further investigation is required to clarify the role of cadmium in the etiology of cadmium-induced bone damage. 
Several population-based studies showed an association between osteoporosis and environmental cadmium exposure. Zhu and colleagues [39] investigated a population living in an area near a lead, zinc, and cadmium smelter and a population in a control area in southeast China. Forearm bone mineral densities of the participants were measured by SPA-4 single-photon absorptiometry. They reported that osteoporosis was significantly prevalent in the heavily polluted area compared with the control area in females over 50 years old, and spontaneous fracture was significantly prevalent in the highly polluted area in subjects over 40 years old. The Swedish OSCAR study investigated workers occupationally exposed to cadmium, subjects environmentally exposed to cadmium living in an area near battery plants, and people residing in an area further away from battery plants. This study showed a negative dose-effect relationship between cadmium dose and bone mineral density measured by DXA for people at the age of 60 or older, and an increasing hazard ratio for forearm fractures with increased urinary cadmium levels for people beyond the age of 50 years [40]. A Japanese study in a non-cadmium-polluted area (Kanazawa City) revealed that the urinary cadmium in subjects with a mean concentration of $2.87 \mu \mathrm{g} / \mathrm{g}$ creatinine showed a significant correlation with NAG but not with $\beta_{2}-\mathrm{MG}-\mathrm{U}$ [41]. That study carried out QUS bone measurements of the calcaneus and demonstrated that the stiffness index, which is used as an index of bone mass, was significantly inversely correlated with urinary cadmium. They emphasized the need for reassessment of the significance of cadmium exposure in the general Japanese population. Horiguchi and colleagues [42] conducted health examinations in 1380 female farmers whose age ranged from 41 to 75 years from five districts in Japan who consumed rice contaminated by low-to-moderate levels of cadmium. They concluded that environmental exposure to cadmium at levels insufficient to induce renal dysfunction does not increase the risk of osteoporosis, strongly supporting the established explanation for bone injury induced by cadmium as a secondary effect, not a direct effect, because the increase in urinary calcium excretion by cadmium exposure occurring at levels much less than the threshold of irreversible renal tubular dysfunction was considered to be due to decreased renal tubular reabsorption.

Akesson and colleagues [38] investigated cadmiumrelated effects on bone in 820 women (53-64 years of age). They reported that urinary cadmium was negatively associated with bone mineral density and parathyroid hormone in blood, and positively associated with urinary deoxypyridinoline and bone alkaline phosphatase in serum. They also stated that the negative effects of low-level cadmium exposure on bone seemed to intensify after menopause. The present study showed a weak positive correlation
(0.124) between cadmium intake and FDPD-U in postmenopausal women, suggesting that the influence of menopause on the effects of cadmium on bone is not denied, while the correlation between cadmium intake and FDPD-U in premenopausal women was 0.055 .

According to the Website of the Japanese Ministry of Agriculture, Forestry and Fisheries [45], the supply of brown rice with cadmium concentrations ranging from 0.4 to $1 \mathrm{mg} / \mathrm{kg}$ has been stopped since 1970 . Sales of brown rice containing cadmium concentrations over $1 \mathrm{mg} / \mathrm{kg}$ have been prohibited and the remaining brown rice was disposed of by incineration, in line with the Food Sanitation Act since 1970. Moreover, the Japanese Ministry of Agriculture, Forestry and Fisheries has designated rice fields where brown rice with cadmium concentrations of over $1 \mathrm{mg} / \mathrm{kg}$ has been harvested as soil-polluted agricultural land requiring countermeasures, and provided guidance to farmers in improving their soil. Cadmium intake in the Japanese people has been decreasing year by year due to such management of rice distribution, as well as a general decrease in rice intake among the Japanese.

The present study revealed a weak positive correlation between bone resorption markers and cadmium intake, $\mathrm{Cd}-\mathrm{U}, \beta_{2}-\mathrm{MG}-\mathrm{U}$, or NAG-U. This suggests the possibility that bone metabolism may be affected by low-grade exposure to cadmium. Because subjects who had a history of renal disease were excluded from this study, it is uncertain whether cadmium affects bone directly without signs of cadmium-induced kidney damage, as Honda and colleagues [41] reported, or whether cadmium affects bone indirectly by causing renal dysfunction. In the present study, ultrasonic bone evaluation did not demonstrate that low-grade exposure to cadmium increased the risk of fracture. In general, women, who often tend to be in an iron-deficient state, are more sensitive to cadmium than men because iron deficiency accelerates the absorption of cadmium from the intestinal tract. Therefore, environmental low-grade exposure to cadmium is considered to influence women more strongly than men. According to a total diet study carried out by the Japanese Ministry of Health, Labour and Welfare, the average daily cadmium intake from food for a Japanese person from 2003 to 2007 was $21.9 \mu \mathrm{g} /$ day. The average daily cadmium intake from rice for a Japanese person was $9.8 \mu \mathrm{g} /$ day. The ratio of the daily cadmium intake from rice to that in all daily meals was $44.8 \%$ [46]. When we applied this ratio to our investigation, the cadmium intake from food for one subject was $3.60 \mu \mathrm{g} / \mathrm{kg}$ body weight/week, as cadmium intake from rice was $1.61 \mu \mathrm{g} / \mathrm{kg}$ body weight/week. This value is much smaller than the PTWI of $7 \mu \mathrm{g} / \mathrm{kg}$ body weight/week, which the FAO and JECFA of WHO proposed in 1993, and is equal to $51.4 \%$ of the PTWI. The present study could not determine a cadmium 
burden to the human body which would not affect bone metabolism. From the viewpoint of bone metabolism, the influence of environmental cadmium exposure on human health must not be disregarded, especially among women in Japan, where environmental cadmium exposure is relatively high even in non-polluted areas, compared with other countries. However, the cadmium intake of Japanese people from food has been decreasing year by year. It is necessary to assess the cadmium burden on the human body in long-term follow-up surveys. Furthermore, because multiple factors besides cadmium affect bone metabolism, assessment of bone metabolism disorder based only on cadmium is inappropriate. Further investigation is required to determine the tolerable cadmium intake in circumstances of environmental low-grade cadmium exposure and to elucidate the mechanism of the effect of cadmium on bone metabolism.

Acknowledgments This work was supported in part by research grants-in-aid from the Environment Agency of the Government of Japan to Minoru Sugita from 1993 to 2005. We express special gratitude for the cooperation of the Joetsu Medical Association and Dr. Shin-ichirou Shimbo of Kyoto Women's University. Thanks are also due to Mrs. Chika Onozawa for her skillful work in statistical analysis.

\section{References}

1. Nogawa K, Kobayashi E, Okubo Y, Suwazono Y. Environmental cadmium exposure, adverse effects and preventive measures in Japan. Biometals. 2004;17(5):581-7.

2. WHO. WHO Technical Report Series 837: JECFA 41st. 1993.

3. WHO. Joint FAO/WHO expert committee on food additives 73rd meeting: summary and conclusions. http://www.fao.org/ag/agn/ agns/jecfa/JECFA73\%20Summary\%20Report\%20Final.pdf (2010). Accessed 16 Nov 2010.

4. Committee of Reassessment for Reference Values of Content. The report of result about outsourcing work by the Environmental Agency: the work about reassessment for reference values of content in 1999. Tokyo: Geo-Environmental Protection Center; 2000 (in Japanese).

5. Watanabe T, Zhang ZW, Moon CS, Shimbo S, Nakatsuka H, Matsuda-Inoguchi N, et al. Cadmium exposure of women in general populations in Japan during 1991-1997 compared with 1977-1981. Int Arch Occup Environ Health. 2000;73(1):26-34.

6. Watanabe T, Shimbo S, Moon CS, Zhang ZW, Ikeda M. Cadmium contents in rice samples from various areas in the world. Sci Total Environ. 1996;184(3):191-6.

7. Sugita M. The biological half-time of heavy metals. The existence of a third, "slowest" component. Int Arch Occup Environ Health. 1978;41(1):25-40.

8. Kobayashi S. Effect of aging on the concentration of cadmium, zinc, and copper in human kidney. Jpn J Public Health (Nippon Koshu Eisei Zasshi). 1983;30(1):27-34 (in Japanese with English abstract).

9. Iwata K, Saito H, Moriyama M, Nakano A. Renal tubular function after reduction of environmental cadmium exposure: a tenyear follow-up. Arch Environ Health. 1993;48(3):157-63.

10. Flanagan PR, McLellan JS, Haist J, Cherian G, Chamberlain MJ, Valberg LS. Increased dietary cadmium absorption in mice and human subjects with iron deficiency. Gastroenterology. (1978); 74(5 Pt 1):841-6.

11. Berglund M, Akesson A, Nermell B, Vahter M. Intestinal absorption of dietary cadmium in women depends on body iron stores and fiber intake. Environ Health Perspect. 1994;102(12): 1058-66.

12. WHO. WHO Food Additive Series, No. 46: JECFA 55th. 2001.

13. Järup L. Cadmium overload and toxicity. Nephrol Dial Transplant. 2002;17(Suppl 2):35-9.

14. Rivai IF, Koyama H, Suzuki S. Cadmium content in rice and its daily intake in various countries. Bull Environ Contam Toxicol. 1990;44(6):910-6.

15. Sasaki S, Yanagibori R, Amano K. Self-administered diet history questionnaire developed for health education: a relative validation of the test-version by comparison with 3-day diet record in women. J Epidemiol. 1998;8(4):203-15.

16. Sasaki S, Ushio F, Amano K, Morihara M, Todoriki O, Uehara Y, et al. Serum biomarker-based validation of a self-administered diet history questionnaire for Japanese subjects. J Nutr Sci Vitaminol (Tokyo). 2000;46(6):285-96.

17. Sasaki S, Kobayashi M, Tsugane S. Validity of a self-administered food frequency questionnaire used in the 5-year follow-up survey of the JPHC Study Cohort I: comparison with dietary records for food groups. J Epidemiol. 2003;13(1 Suppl):S57-63.

18. Tsubono Y, Takamori S, Kobayashi M, Takahashi T, Iwase Y, Iitoi $\mathrm{Y}$, et al. A data-based approach for designing a semiquantitative food frequency questionnaire for a population-based prospective study in Japan. J Epidemiol. 1996;6(1):45-53.

19. Tsugane S, Kobayashi M, Sasaki S. Validity of the self-administered food frequency questionnaire used in the 5-year follow-up survey of the JPHC Study Cohort I: comparison with dietary records for main nutrients. J Epidemiol. 2003;13(1 Suppl):S51-6.

20. Nakadaira H, Nishi S. Effects of low-dose cadmium exposure on biological examinations. Sci Total Environ. 2003;308(1-3): 49-62.

21. Naka H. Quantitative ultrasonic bone evaluation: the device of ultrasonic bone evaluation-AOS-100. Jpn J Clin Med (Nippon Rinsho). 2004;62(Suppl 2):299-304 (in Japanese).

22. Morii H, Rowe SM, Chung SS, Park CJ, Kang JC, Kee HS, et al. Bone mineral in elderly people in Sangsa Village, Korea. Chonnam J Med Sci. 1995;8(2):146-54.

23. Krieg MA, Thiébaud D, Burckhardt P. Quantitative ultrasound of bone in institutionalized elderly women: a cross-sectional and longitudinal study. Osteoporos Int. 1996;6(3):189-95.

24. Turner CH, Peacock M, Timmerman L, Neal JM, Johnston CC Jr. Calcaneal ultrasonic measurements discriminate hip fracture independently of bone mass. Osteoporos Int. 1995;5(2):130-5.

25. Hans D, Dargent-Molina P, Schott AM, Sebert JL, Cormier C, Kotzki PO, et al. Ultrasonographic heel measurements to predict hip fracture in elderly women: the EPIDOS prospective study. Lancet. 1996;348(9026):511-4.

26. Yoh K. QUS and DXA (heel scan) in calcaneus. Jpn J Clin Med (Nippon Rinsho). 2007;65 (Suppl 9):163-70 (in Japanese).

27. Watanabe T, Nakatsuka H, Satoh H, Yamamoto R, Ikeda M. Reduced dietary cadmium intake in past 12 years in a rural area in Japan. Sci Total Environ. 1992;119:43-50.

28. National Institute of Health Sciences of Japan. Total Diet Survey in Japan. Tokyo: National Institute of Health Sciences of Japan; 2003 (in Japanese).

29. Zhang ZW, Moon CS, Watanabe T, Shimbo S, He FS, Wu YQ, et al. Background exposure of urban populations to lead and cadmium: comparison between China and Japan. Int Arch Occup Environ Health. 1997;69(4):273-81.

30. Watanabe T, Nakatsuka H, Ikeda M. Cadmium and lead contents in rice available in various areas of Asia. Sci Total Environ. 1989;80(2-3):175-84. 
31. Nogawa K, Kawano S, Kato T, Sakamoto M. The prevalence of itai-itai disease and the mean cadmium concentration in rice produced by individual villages. Jpn J Hyg (Nippon Eiseigaku Zasshi). 1983;37(6):843-7 (in Japanese with English abstract).

32. Aoshima K, Iwata K, Kasuya M. Environmental exposure to cadmium and effects on human health. Part 2. Bone and mineral metabolism in inhabitants of the cadmium-polluted Jinzu River basin in Toyama Prefecture. Jpn J Hyg (Nippon Eiseigaku Zasshi). 1988;43(4):864-71 (in Japanese with English abstract).

33. Kozuka H. Interactive exhibition of heavy metal toxicity in bone metabolism. From the viewpoint of deductive toxicology. J Pharm Soc Jpn (Yakugaku Zasshi). 1995;115(3):157-69 (in Japanese with English abstract).

34. Ogoshi K, Nanzai Y, Moriyama T. Decrease in bone strength of cadmium-treated young and old rats. Arch Toxicol. 1992;66(5): 315-20.

35. Miyahara T, Kozuka H. The direct effect of cadmium on bone metabolism and interaction between cadmium and zinc or copper in tissue culture. Jpn J Toxicol Environ Health (Eisei Kagaku). 1985;31(2):59-71 (in Japanese with English abstract).

36. Ohta H, Yamauchi Y, Nakakita M, Tanaka H, Asami S, Seki Y, et al. Relationship between renal dysfunction and bone metabolism disorder in male rats after long-term oral quantitative cadmium administration. Ind Health. 2000;38(4):339-55.

37. Coonse KG, Coonts AJ, Morrison EV, Heggland SJ. Cadmium induces apoptosis in the human osteoblast-like cell line Saos-2. J Toxicol Environ Health A. 2007;70(7):575-81.

38. Akesson A, Bjellerup P, Lundh T, Lidfeldt J, Nerbrand C, Samsioe G, et al. Cadmium-induced effects on bone in a population-based study of women. Environ Health Perspect. 2006; 114(6):830-4.
39. Zhu G, Wang H, Shi Y, Weng S, Jin T, Kong Q, et al. Environmental cadmium exposure and forearm bone density. Biometals. 2004;17(5):499-503.

40. Järup L, Alfvén T. Low level cadmium exposure, renal and bone effects-the OSCAR study. Biometals. 2004;17(5):505-9.

41. Honda R, Tsuritani I, Noborisaka Y, Suzuki H, Ishizaki M, Yamada Y. Urinary cadmium excretion is correlated with calcaneal bone mass in Japanese women living in an urban area. Environ Res. 2003;91(2):63-70.

42. Horiguchi H, Oguma E, Sasaki S, Miyamoto K, Ikeda Y, Machida M, et al. Environmental exposure to cadmium at a level insufficient to induce renal tubular dysfunction does not affect bone density among female Japanese farmers. Environ Res. 2005;97(1):83-92.

43. Barr DB, Wilder LC, Caudill SP, Gonzales AJ, Needham LL, Pirkle JL. Urinary creatinine concentrations in the U.S. population: implications for urinary biologic monitoring measurements. Environ Health Perspect. 2005;113(7):192-200.

44. Hayashi Y. The study about general assessment of risk on health by cadmium exposure. Rep Environ Public Health (Kankyo Hoken Report). 2005;69:55-120 (in Japanese).

45. The Japanese Ministry of Agriculture, Forestry and Fisheries. Information about cadmium content in food. http://www.maff.go. jp/cd/html/B1.htm (2008). Accessed 18 Dec 2008 (in Japanese).

46. The Japanese Ministry of Agriculture, Forestry and Fisheries. Risk profile sheet about safety of food (for assessment conference) (chemical materials). http://www.maff.go.jp/j/syouan/ seisaku/risk_analysis/priority/pdf/chem_cd.pdf (2009). Accessed 7 May 2009 (in Japanese). 